\title{
Esophageal stricture following successful resolution of a mediastinal pseudocyst by endoscopic trans- papillary drainage
}

A 42-year-old alcoholic man had recurrent upper abdominal pain accompanied by breathlessness and right-side pleuritic chest pain for 5 months. Examination revealed right-sided pleural effusion. He had normal hemogram, liver, and renal function tests, normal serum amylase and a normal calcium profile. Thoracentesis from the right-sided pleural effusion revealed no cells, a high protein content $(4.3 \mathrm{~g} / \mathrm{dL})$, and elevated amylase (2800 IU/L). Tube drainage of the right pleural effusion was done; it continued to drain $200-400 \mathrm{~mL} /$ day of clear fluid with a high amylase content.

A contrast-enhanced computed tomography (CECT) scan of the chest and abdomen showed a small abdominal pseudocyst (pancreatic pseudocyst), right-sided pleural effusion, and a 5-cm pseudocyst in the posterior mediastinum compressing the lower end of the esophagus with its proximal dilatation ( Fig. 1). Endoscopic ultrasound (EUS) revealed features of chronic noncalcific pancreatitis along with a mediastinal pseudocyst that was displacing the descending aorta posteriorly ( Fig.2). Endoscopic retrograde cholangiopancreatography (ERCP) was performed. Contrast-free deep cannulation of the pancreatic duct was achieved ( Fig. 3), and a 5-Fr pancreatic stent was placed.

The patient had marked improvement in his symptoms, with resolution of abdominal pain and cessation of chest tube drainage within 2 weeks of stent insertion. The chest tube was removed, and repeat CECT of the chest and abdomen at 4 weeks showed resolution of all the pseudocysts and pleural effusion.

However, the patient started complaining of dysphagia to solids, which gradually worsened. Endoscopy revealed a nonnegotiable stricture at the lower end of the esophagus. EUS with a radial echoendoscope from the mouth of the stricture revealed thickening of the esophageal wall with loss of the layered pattern of the esophageal wall ( Fig.4). Endoscopic dilation was performed with bougie dilators, and the stricture was gradually dilated up to $15 \mathrm{~mm}$ in diameter. With this, there was marked improvement in the pa-

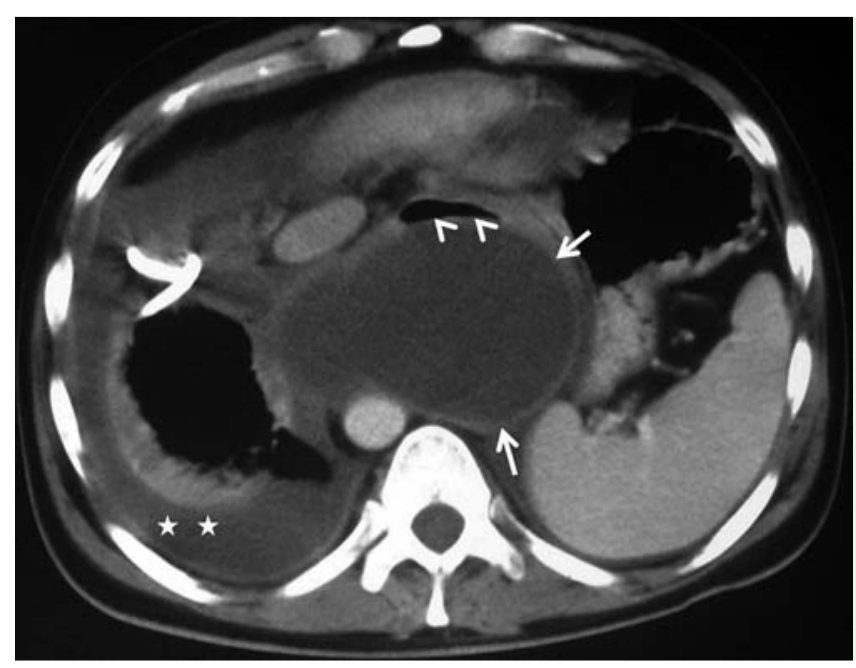

Fig. 1 Contrastenhanced computed tomography (CECT): mediastinal pseudocyst (white arrows) compressing the esophagus with its proximal dilatation (arrow heads). Also note the right-side pleural effusion (stars) with intercostal draining tube in situ.

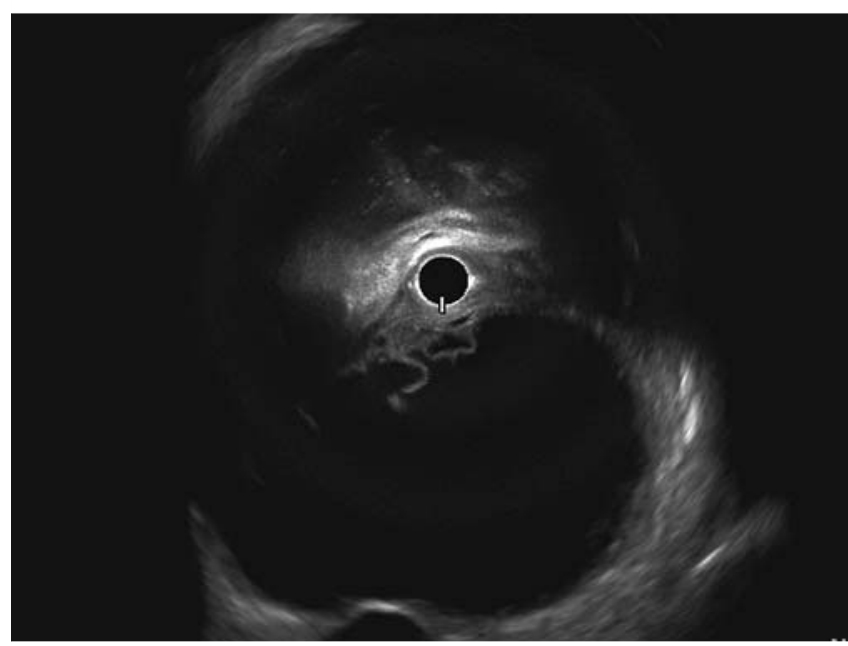

Fig. 2 Endoscopic ultrasound (EUS): pseudocyst in the paraesophageal location anterior to the descending aorta.

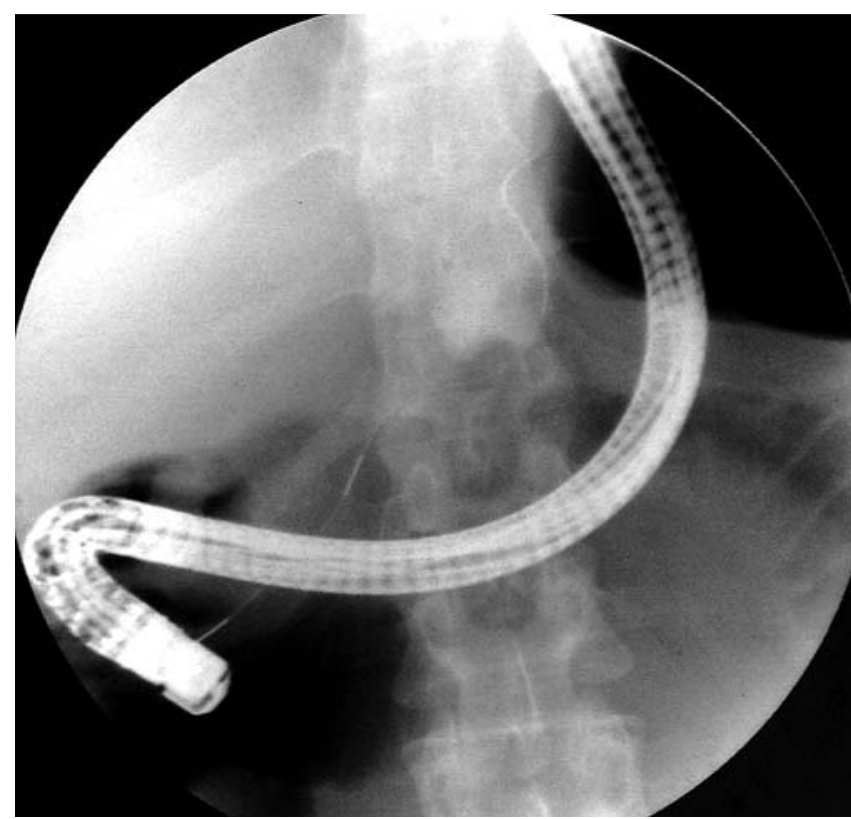

Fig. 3 Endoscopic retrograde pancreatography (ERP): guide wire taken into the area of pancreatic duct disruption in the mediastinum. 


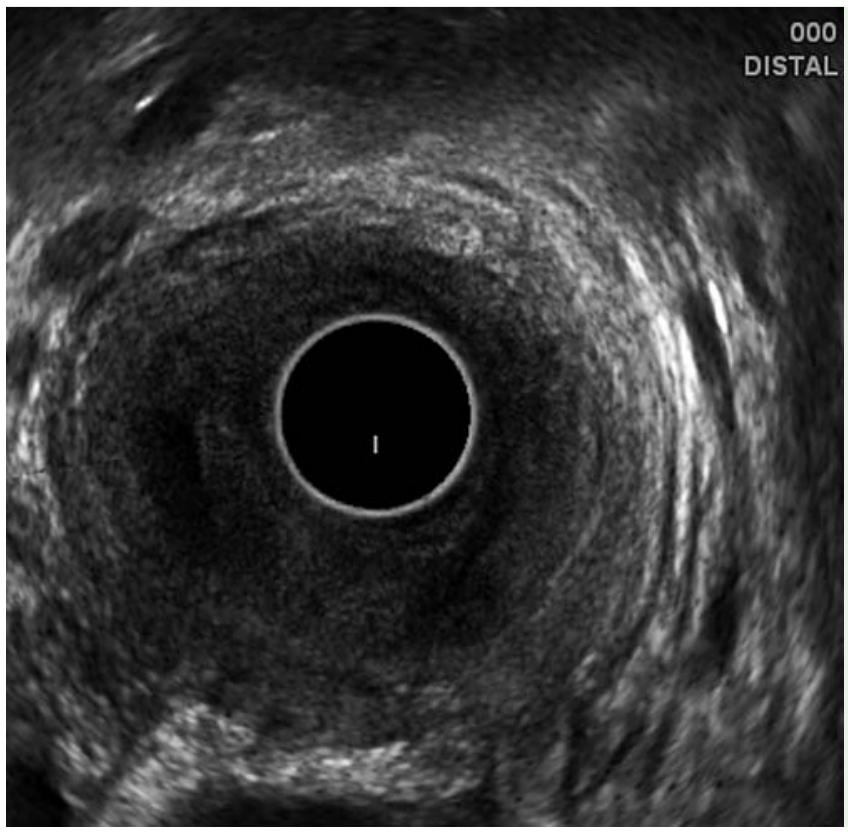

Fig. 4 Endoscopic ultrasound (EUS): marked asymmetrical thickening of the esophageal wall with loss of its layered pattern.

tient's symptoms. After 3 months of follow-up, the patient remained asymptomatic.

In spite of their location, mediastinal pseudocysts rarely cause dysphagia and are usually associated with pleural effusion [1 - 3]. Conservative medical therapy with somatostatin or its analogues and endoscopic (transpapillary or transmural drainage), surgical, or percutaneous drainage methods have been successfully used for symptomatic mediastinal pancreatic pseudocysts [1]. Resolution is usually uneventful, but sometimes the healing process may cause intense fibrotic ing complications [4].

Competing interests: None

\section{S. S. Rana, D. K. Bhasin, C. Rao, H. Singh, V. Sharma, K. Singh}

Department of Gastroenterology, Post Graduate Institute of Medical Education and Research (PGIMER), Chandigarh, India

\section{References}

1 Bhasin DK, Rana SS, Nanda $M$ et al. Endoscopic management of pancreatic pseudocysts at atypical locations. Surg Endosc 2010; 24: 1085-1091

2 Bhasin DK, Rana SS, Chandail VS et al. Successful resolution of a mediastinal pseudocyst and pancreatic pleural effusion by endoscopic nasopancreatic drainage. JOP 2005; 6: 359-364

3 Casson AG, Inculet R. Pancreatic pseudocyst: an uncommon mediastinal mass. Chest 1990; 98: 717-718

4 Bhasin DK, Rana SS, Chandail VS et al. Secondary gastric volvulus following successful resolution of a large perisplenic pseudocyst by endoscopic transpapillary nasopancreatic drainage. Gastrointest Endosc 2007; 65: 940-942

\section{Bibliography}

DOI http://dx.doi.org/

10.1055/s-0031-1291695

Endoscopy 2012; 44: E121-E122

(c) Georg Thieme Verlag KG

Stuttgart · New York

ISSN 0013-726X

reaction in the surrounding tissues, caus-

Endoscopy_UCTN_Code_CCL_1AB_2AC_3AD

\section{Corresponding author}

\section{S. S. Rana, DM}

Department of Gastroenterology

Post Graduate Institute of Medical Education

and Research (PGIMER)

Chandigarh - 160012

India

Fax: +91-172-2744401 drsurinderrana@yahoo.co.in 